\title{
Sistem Informasi Pemilihan Peserta Program Indonesia Pintar (PIP) Dengan Metode K-Nearest Neighbor pada SD Negeri Pejuang V Kota Bekasi
}

\author{
Sandy Satyo Prihatin ${ }^{1}$, Prima Dina Atika ${ }^{1,{ }^{\star}}$, Herlawati ${ }^{1}$ \\ * Korespondensi: e-mail: prima.dina@dsn.ubharajaya.ac.id
}

\begin{abstract}
1 Informatika; Universitas Bhayangkara Jakarta Raya; JI. Raya Perjuangan Bekasi Utara, Kota Bekasi, 88955882 / 88955871; e-mail: sandysatyop@gmail.com, prima.dina@dsn.ubharajaya.ac.id, herlawati@dsn.ubharajaya.ac.id
\end{abstract}

$\begin{array}{ll}\text { Submitted } & \text { : } 9 \text { Agustus } 2021 \\ \text { Revised } & : \text { 20 September } 2021 \\ \text { Accepted } & : 28 \text { Oktober } 2021 \\ \text { Published } & : 30 \text { November } 2021\end{array}$

\begin{abstract}
The selection of participants for the Smart Indonesia Program (PIP) is an activity to determine students who are eligible for assistance. This study aims to create an information system for the Selection of Participants for the Smart Indonesia Program (PIP) which will assist Administrative Staff and SD Negeri Pejuang V Bekasi City in determining eligible and ineligible participants for assistance. The method used in this information system uses the K-Nearest Neighbor algorithm. The K-Nearest Neighbor process is carried out by giving weight to the student data attributes and looking for the Euclidean distance, then sorted from the smallest distance, after sorting the student data then looking for the closest distance to the training data. The K-Nearest Neighbor algorithm in data training is very fast, simple, easy to learn, effective with large training data and is resistant to data containing incorrect or anomalous values. The results of this study obtained student data as many as 77 students, there are True Positive (TP) data of 5 data, False Positive (FN) of 7 data, True Negative (TN) of 65 data and False Negative (FP) of 0 . Results The accuracy obtained is $90.90 \%$ with a value of $k=10$.
\end{abstract}

Keywords: Information System, K-Nearest Neighbor, KNN, Program Indonesia Pintar (PIP).

\section{Abstrak}

Pemilihan peserta Program Indonesia Pintar (PIP) merupakan kegiatan menentukan siswa yang layak untuk mendapatkan bantuan. Penelitian ini bertujuan membuat sistem informasi untuk Pemilihan Peserta Program Indonesia Pintar (PIP) yang akan membantu Staff Administrasi dan pihak SD Negeri Pejuang $V$ Kota Bekasi dalam menentukan peserta yang layak dan tidak layak untuk mendapat bantuan. Metode yang digunakan pada sistem informasi ini menggunakan algoritma KNearest Neighbor. Proses K-Nearest Neighbor ini dilakukan dengan memberikan bobot pada atribut data siswa dan mencari jarak Euclidean, selanjutnya diurutkan dari jarak yang terkecil, setelah diurutkan data siswa tersebut maka dicari jarak terdekat terhadap data training. Algoritma K-Nearest Neighbor dalam pelatihan data sangat cepat, sederhana, mudah dipelajari, efektif dengan data pelatihan besar serta tahan terhadap data berisi nilai yang salah atau anomali. Hasil dari penelitian ini data siswa yang didapat sebanyak 77 siswa, terdapat data True Positive (TP) sejumlah 5 data, False Positive (FP) sejumlah 7 data, True Negative (TN) sejumlah 65 data dan False Negative (FN) sejumlah 0. Hasil akurasi yang diperoleh mendapatkan nilai $90.90 \%$ dengan nilai $\mathrm{k}=10$.

Kata kunci: K-Nearest Neighbor, KNN, Program Indonesia Pintar (PIP), Sistem Informasi. 


\section{Pendahuluan}

Pemerintah berupaya meningkatkan taraf pendidikan bagi masyarakat Indonesia, salah satunya melalui Program Indonesia Pintar (PIP), program bantuan dana dalam bentuk Kartu Indonesia Pintar (KIP) yang bertujuan membantu biaya personal pendidikan bagi peserta didik miskin atau rentan miskin yang terdaftar sebagai peserta didik pendidikan dasar dan menengah (Kemendikbud, 2020), agar tetap mendapatkan layanan pendidikan sampai tamat pendidikan menengah, baik melalui jalur pendidikan formal maupun non formal (Kemdikbud, 2021).

Penerapan K-Nearest Neighbor dalam penerimaan peserta didik dengan sistem zonasi Metode K-Nearest Neighbor bekerja berdasarkan asumsi bahwa suatu data akan memiliki kelas atau kategori yang sama dengan data yang berada disekitarnya, penelitian ini memiliki akurasi sebesar $83,36 \%$ dengan data latih sebanyak 35 data (Kurniawan \& Saputra, 2019). K-Nearest Neighbor memiliki kelemahan dalam menentukan nilai k yang tepat untuk menghasilkan akurasi sistem yang terbaik namun memiliki kelebihan kepada training data set yang memiliki banyak noise serta efektif terhadap jumlah data training tinggi/besar (Harsemadi et al., 2017), namun metode KNN lebih efektif digunakan dalam mengambil keputusan dengan adanya pembagian data menjadi $70 \%$ data training dan 30\% data testing (Latifah et al., 2017; Yulianti \& Nurdin, 2018). Pada penelitian lain penentuan kriteria atau atribut berdasarkan data yang didapat seperti jarak latitude dan longitude, nilai rata-rata rapor, dalam bentuk kuesioner yang berisi kondisi sosial ekonomi dan asset siswa tersebut. Pada penelitian ini memiliki perbedaan yaitu data yang didapat dengan atribut/kriteria pekerjaan orang tua, status orang tua, penghasilan orang tua dan jumlah tanggungan orang tua sesuai dengan kelengkapan detail isi pendataan siswa oleh Kemdikbud.

Proses pemilihan peserta PIP dilakukan oleh pegawai sekolah hanya melihat berdasarkan surat pendukung saja, ini menyebabkan kurangnya ketepatan dan terjangkaunya pemerataan bantuan untuk peserta yang belum terdaftar. Dengan metode $\mathrm{K}$-Nearest Neighbor, data peserta akan dikategorikan berdasarkan layak atau tidaknya untuk mendapatkan PIP. Peserta yang layak dipilih untuk mendapatkan bantuan ditentukan dengan memberikan nilai pada setiap kriteria. Kriteria tersebut memiliki bobot yang sudah ditentukan oleh kesepakatan pihak sekolah, sehingga setiap bobot memiliki nilai penilaian. Bobot nilai setiap kriteria yang dimiliki peserta akan dibandingkan dengan peserta lain. Untuk memperoleh hasil penilaian bobot peserta dapat diperoleh dengan menggunakan metode K-Nearest Neighbor.

SD Negeri Pejuang V Kota Bekasi sebagai salah satu lembaga pendidikan formal yang berada dibawah naungan Dinas Pendidikan Kota Bekasi, ikut dalam menjalankan PIP. Siswa yang diberikan bantuan PIP yang layak dan sesuai dengan ketentuan akan menerima bantuan pada setiap tahun. Beberapa komponen dalam pemilihan peserta PIP diantaranya nilai ujian akhir semester, penghasilan orang tua, dan jumlah tanggungan orang tua. Pada saat penelitian dilakukan proses pemilihan peserta PIP SD Negeri Pejuang V Kota Bekasi dilakukan oleh Staff Administrasi, berdasarkan komponen surat pendukung tanpa kriteria-kriteria lain dari siswa. 
Proses seleksi dengan sistem manual rentan terjadi kesalahan pemilihan peserta sehingga butuh sistem yang didukung oleh algoritma. Sehingga dengan sistem informasi pemilihan peserta PIP menggunakan dengan metode K-Nearest Neighbor, diharapkan dapat memudahkan pihak sekolah dalam ketepatan pemilihan.

\section{Metode Penelitian}

Metode penelitian berisi kerangkan pemikiran yang merupakan alur kegiatan penelitian yang dilakukan, pengumpulan data dengan melakukan survei dan wawancara, algoritma $K$ Nearest Neighbor (KNN) yang digunakan untuk menentukan pemilihan peserta penerima PIP, dan flowchart K-Nearest Neighbor menggambarkan alur bagaimana algoritma $K N N$ secara logis menyelesaikan masalah.

\section{Kerangka Penelitian}

Menggambarkan alur penelitian yang dilakukan berdasarkan teori. Berikut merupakan kerangka penelitian sistem informasi pemilihan peserta PIP. Kerangka penelitian ini dapat dilihat pada gambar 1 .

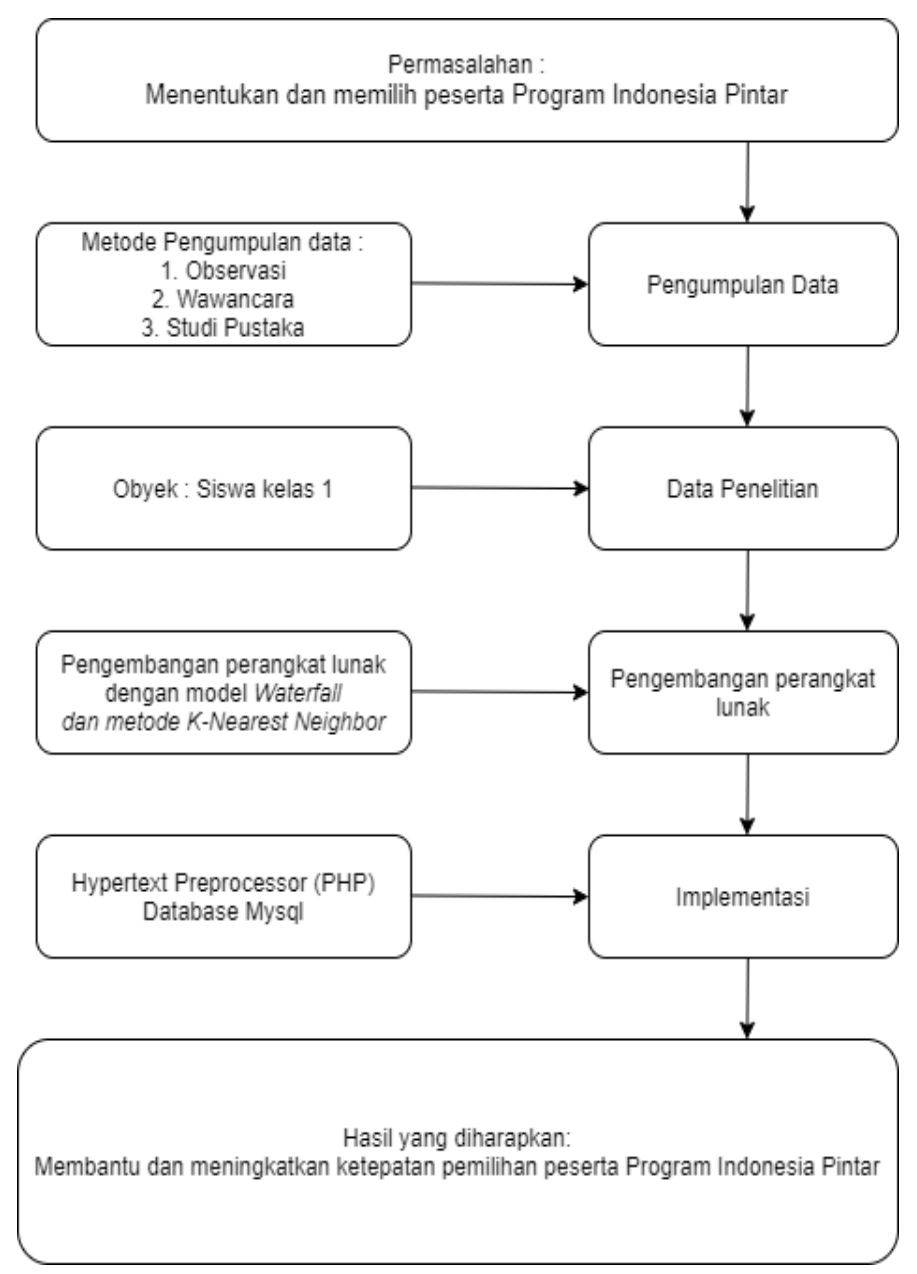

Sumber: Hasil Penelitian (2021)

Gambar 1. Kerangka Penelitian 


\section{Metode Pengumpulan Data}

Pada penelitian ini dilakukan pengumpulan data secara observasi ke SD Negeri Pejuang $\mathrm{V}$ Kota Bekasi mengambil data pendukung dari bagian Administrasi Tata Usaha dengan mengamati dan mempelajari data, serta melakukan wawancara secara langsung dan tidak terstruktur kepada Staff Administrasi untuk mendapatkan data yang berkaitan dengan pelaksanaan proses pemilihan peserta penerima PIP.

\section{Algoritma K-Nearest Neighbor}

Sistem informasi berupa komponen-komponen yang berkaitan dengan proses pembuatan dan pendistribusian informasi agar dapat digunakan oleh pengguna (user) dibangun berdasarkan algoritma yang berisi urutan langkah-langkah secara logis untuk menyelesaikan masalah (Negara et al., 2021; Ropianto et al., n.d.). K-Nearest Neighbor (KNN) termasuk kelompok instance-based learning algoritma ini juga merupakan salah satu teknik lazy learning. KNN dilakukan dengan mencari kelompok $\mathrm{k}$ objek dalam data training yang paling dekat (mirip) dengan objek pada data baru atau data testing (Argina, 2020). K-Nearest Neighbor bekerja berdasarkan suatu data memiliki kelas atau kategori yang sama dengan data yang berada disekitarnya sebagai ketetanggaan. Euclidean Distance atau jarak Euclidean untuk mencari jarak antara dua titik dalam ruang dua dimensi menggunakan persamaan 1 (D T Larose, 2005).

$d_{\text {Euclidean }}(x, y)=\sqrt{\sum_{i}\left(x_{i}-y_{i}\right)^{2}}$

Sumber: (D T Larose, 2005)

Keterangan:

d: jarak Euclidean

$\mathrm{x}_{\mathrm{i}}$ : nilai pada data training $\mathrm{ke}-\mathrm{i}$

$\mathrm{y}_{\mathrm{i}}$ : nilai pada data testing $\mathrm{ke}-\mathrm{i}$

$\Sigma$ : banyaknya atribut datas

Tingkat akurasi sebuah klasifikasi adalah rasio perbandingan jumlah data testing yang dapat diklasifikasikan dengan benar dengan jumlah seluruh data testing. Untuk mencari tingkat akurasi dapat dilihat pada persamaan 2 (Daniel T Larose \& Larose, 2014).

$$
\text { Akurasi }=\frac{\text { banyaknya prediksi yang benar }}{\text { total banyak prediksi }} * 100 \%
$$

Sumber: Larose (2014)

Pada gambar 2 merupakan Flowchart dari K-Nearest Neighbor, persamaan diawali dengan memasukkan nilai k, data latih dan data yang akan diuji dengan target. Setelah data telah disiapkan lalu proses normalisasi data untuk menjadikan nilai data lebih kecil. Kemudian lakukan perhitungan jarak euclidean untuk menghasilkan nilai jarak, lakukan pada seluruh data 
lalu urutkan data tersebut dari nilai terkecil. Lalu pilih jumlah target yang muncul lebih banyak, maka hasil klasifikasi K-Nearest Neighbor ditemukan. Syarat menentukan hasil yaitu memiliki target hasil yang muncul dengan jumlah terbanyak.

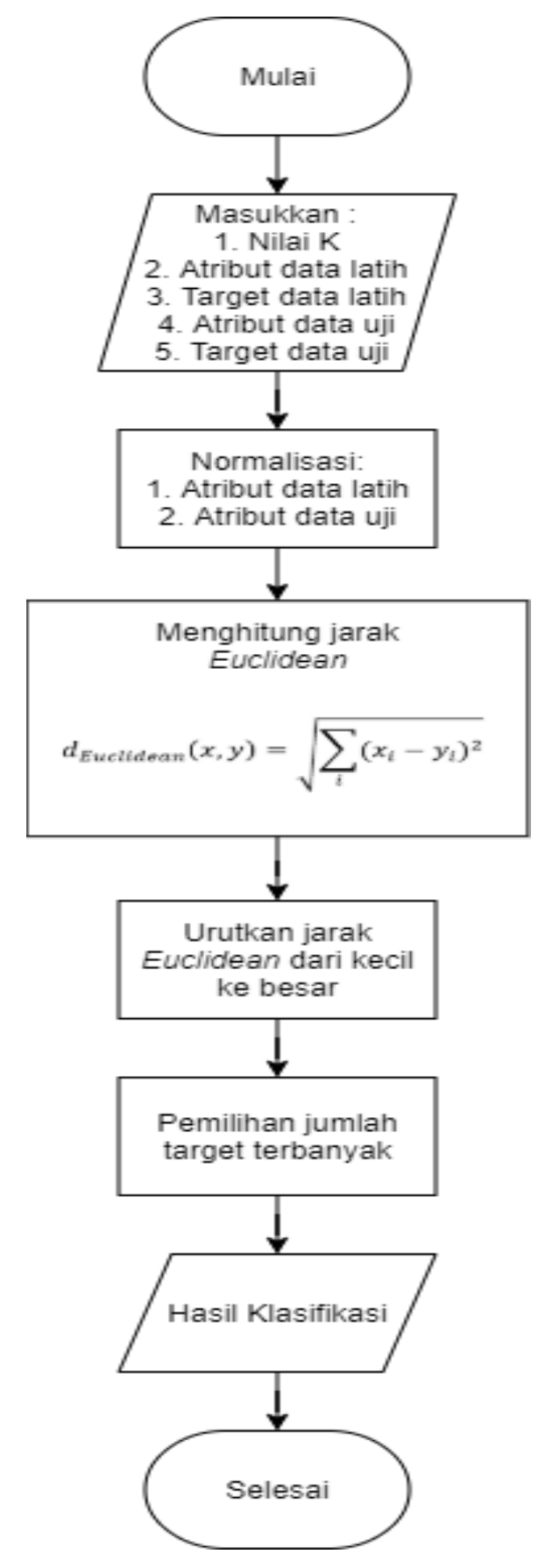

Sumber: Hasil Penelitian (2021)

Gambar 2. Flowchart K-Nearest Neighbor

\section{Hasil dan Pembahasan}

Sesuai permasalahan yang tditeliti yaitu perlunya dibangun sistem informasi Pemilihan Peserta Program Indonesia Pintar (PIP), berikut tahapan sesuai dengan kerangka penelitian dan algoritma K-Nearest Neighbor. 


\section{Desain Sistem Informasi Pemilihan Peserta PIP}

Penggunaan sistem pemilihan peserta PIP pada SD Negeri Pejuang $\mathrm{V}$ yang ada sekarang ini belum memenuhi standar perkembangan teknologi dimasa kini, dikarenakan sistem yang ada masih dilakukan secara manual. Sistem pemilihan berdasarkan melihat berkas pendukung, ini dapat menyebabkan perlu waktu yang cukup lama dan terjadinya human error. Untuk menyelesaikan masalah yang terjadi maka mamanfaatkan dan mengoptimalkan perkembangan teknologi dengan desain sistem informasi yang di rancang seperti gambar 3 .

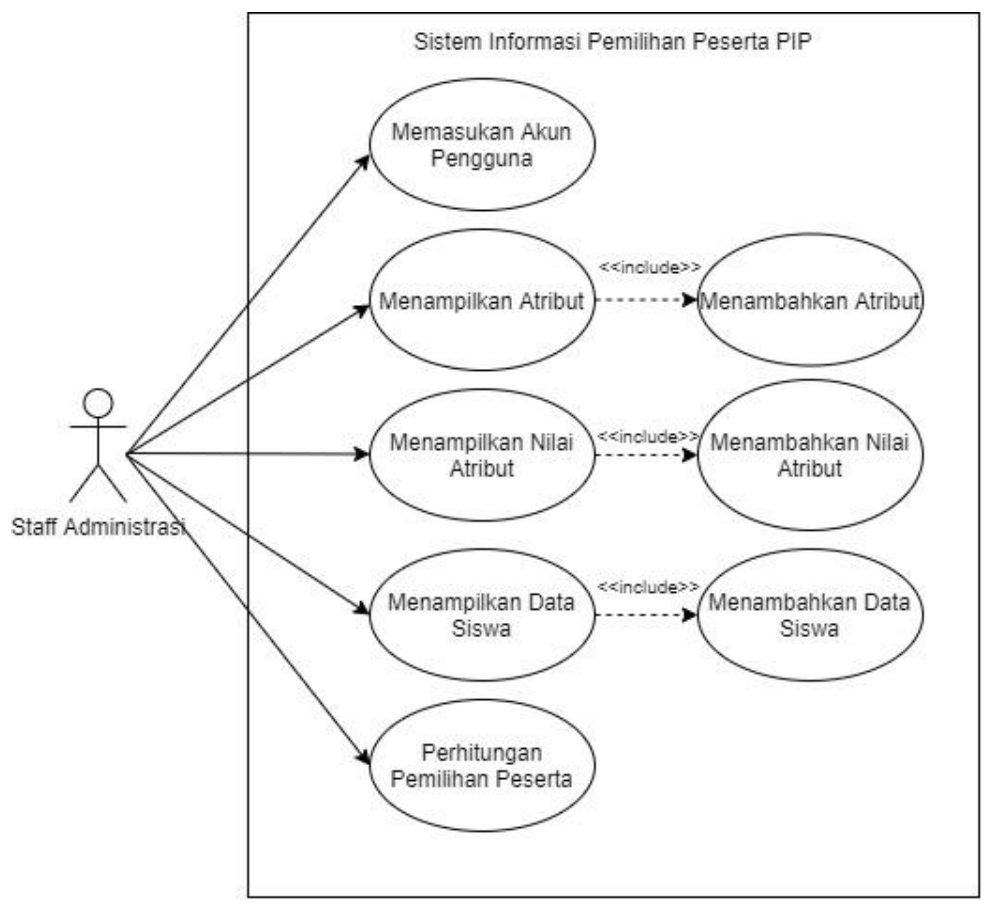

Sumber: Hasil Penelitian (2021)

Gambar 3. Use Case Diagram

Adapun urutan prosedur dari sistem berjalan pada sisi Staff Administrasi sebagai berikut (a) Staff Administrasi membuka form login; (b) Staff Administrasi mengisi form login dengan username dan password; (c) Staff Administrasi berhasil login dan diarahkan ke halaman Data Siswa. Terdapat menu Atribut, Nilai Atribut, Data Siswa, dan Perhitungan; (d) Staff Administrasi mengklik Atribut untuk dapat mengisi nama Atribut, Status Atribut, Nilai Atribut, dan Keterangan, (e) Staff Administrasi mengklik Nilai Atribut untuk mengisi Nama Atribut dan Nilai Atribut; (f) Staff Administrasi mengklik Data Siswa untuk mengisi data siswa dengan nama atribut dan nilai atribut yang telah ditentukan; (g) Staff Administrasi mengklik Perhitungan untuk mencari hasil dalam kelayakan siswa menerima PIP.

\section{Penerapan Metode K-Nearest Neighbor}

a. Menentukan atribut dan nilai atribut

Atribut dan nilai atribut ditentukan berdasarkan data siswa yang dihasilkan dari pengumpulan data. Adapun penjelasan Atribut dan nilai atribut yang digunakan sebagaimana tabel 1 . 
Tabel 1. Tabel Atribut dan Nilai Atribut

\begin{tabular}{lll}
\hline \multicolumn{1}{c}{ Nama Atribut } & \multicolumn{1}{c}{ Nilai Atribut } \\
\hline Pekerjaan Orang Tua & 1. & Pegawai Negeri/BUMN \\
& 2. & Karyawan Swasta/Wiraswasta \\
& 3. Wirausaha/Pedagang \\
& 4. & Ibu Rumah Tangga \\
& 5. & Buruh \\
\hline Status Orang Tua & 1. Normal \\
& 2. Hanya Ayah \\
& 3. Hanya lbu \\
\hline Penghasilan Orang Tua & 4. Yatim Piatu \\
\hline Jumlah Tanggungan Orang Tua & - & \\
\hline Hasil (Target) & - & \\
\hline Sumber: Pengolahak & 2. Layak \\
\hline
\end{tabular}

Sumber: Pengolahan Data (2021)

Selanjutnya menentukan bobot pada masing-masing Nilai Atribut. Adapun bobot yang telah ditentukan, diantaranya penjelasan yang terdapat pada tabel 2. Atribut pekerjaan orang tua dan status diperlukan sebagai kriteria dalam seleksi penerima PIP agar lebih tepat sasaran karena sasaran utama dari PIP bagi peserta didik miskin atau rentan miskin.

Tabel 2. Bobot Pekerjaan dan Status Orang Tua

\begin{tabular}{|c|c|}
\hline Atribut & Bobot \\
\hline \multicolumn{2}{|l|}{ Pekerjaan Orang Tua } \\
\hline Pegawai Negeri/BUMN & 1 \\
\hline Karyawan Swasta/Wiraswasta & 2 \\
\hline Wirausaha/Pedagang & 3 \\
\hline Ibu Rumah Tangga & 4 \\
\hline Buruh & 5 \\
\hline \multicolumn{2}{|l|}{ Status Orang Tua } \\
\hline Normal & 1 \\
\hline Hanya Ayah & 2 \\
\hline Hanya lbu & 3 \\
\hline Yatim Piatu & 4 \\
\hline
\end{tabular}

Sumber: Pengolahan Data (2021)

b. Data siswa (data training dan data testing)

Data training dan data testing dari data siswa yang didapat, dimiliki 77 dataset, kemudian dibagi menjadi $90 \%$ data training, $10 \%$ data testing atau 70 data training dan 7 data yang akan diuji. Setelah data siswa disiapkan maka data akan melakukan pemberian nilai dan bobot. Masing-masing data dapat dilihat pada tabel 3.

Tabel 3. Bobot Data Siswa

\begin{tabular}{ccrrrr}
$\begin{array}{c}\text { No } \\
\text { Dataset }\end{array}$ & $\begin{array}{c}\text { Pekerjaan } \\
\text { Orang Tua }\end{array}$ & $\begin{array}{c}\text { Status } \\
\text { Orang Tua }\end{array}$ & $\begin{array}{c}\text { Penghasilan } \\
\text { Orang Tua }\end{array}$ & $\begin{array}{c}\text { Jumlah Tanggungan } \\
\text { Orang Tua }\end{array}$ & Hasil \\
\hline 202001 & 1 & 1 & 4500000 & 2 & Tidak \\
\hline 202002 & 1 & 1 & 4300000 & 1 & Tidak \\
\hline 202003 & 2 & 2 & 3500000 & 2 & Tidak \\
\hline 202004 & 4 & 1 & 2500000 & 2 & Tidak \\
\hline 202005 & 2 & 1 & 6700000 & 2 & Tidak \\
\hline 202076 & 4 & 1 & 500000 & 3 & Tidak \\
\hline$\ldots$ & $\ldots$ & $\ldots$ & $\ldots$ & $\ldots$ & 3 \\
\hline 202077 & 3 & 3 & 750000 & & Ya \\
\hline Sumber: Pengolahan Data $(2021)$ & & & &
\end{tabular}


C. Normalisasi data

Normalisasi data dilakukan guna mempersiapkan data agar lebih baik dengan nilai yang kecil. Data lama merupakan nilai data dari atribut yang belum diubah/normalisasi. sedangkan data maksimum adalah nilai terbesar data dari atribut yang belum diubah/normalisasi. Data lama akan dilakukan perubahan menjadi data baru dengan membaginya dengan data maksimum atribut yang ditentukan. Normalisasi data akan dilakukan pada keseluruhan data. Data normalisasi yang telah diubah dapat dilihat pada tabel 4.

Tabel 4. Normalisasi Data

\begin{tabular}{ccccc}
\hline No Dataset & $\begin{array}{c}\text { Pekerjaan Orang } \\
\text { Tua }\end{array}$ & Status Orang Tua & $\begin{array}{c}\text { Penghasilan } \\
\text { Orang Tua }\end{array}$ & $\begin{array}{c}\text { Jumlah } \\
\text { Tanggungan } \\
\text { Orang Tua }\end{array}$ \\
\hline 202001 & 0.20 & 0.333 & 0.556 & 0.333 \\
\hline 202002 & 0.20 & 0.333 & 0.532 & 0.167 \\
\hline 202003 & 0.40 & 0.667 & 0.433 & 0.333 \\
\hline 202004 & 0.80 & 0.333 & 0.309 & 0.333 \\
\hline 202005 & 0.40 & 0.333 & 0.828 & 0.333 \\
\hline$\ldots$ & $\ldots$ & $\ldots$ & $\ldots$ & $\ldots$ \\
\hline 202077 & 0.60 & 1.000 & 0.093 & 0.500 \\
\hline
\end{tabular}

Sumber: Pengolahan Data (2021)

d. Perhitungan euclidean distance

Pada perhitungan dan pencarian jarak Euclidean, maka dapat dilihat pada dibawah ini persamaan 1. Dengan pengujian tersebut, proses perhitungan dilakukan pada masingmasing atribut. Perhitungan jarak dilakukan pada data uji untuk menemukan nilai jarak Euclidean pada tabel 5.

Tabel 5. Tabel Perhitungan Jarak Euclidean

\begin{tabular}{cc}
\hline No & Perhitungan dan Hasil mencari Jarak Euclidean \\
\hline 1 & $D 1=\sqrt{(0.20-0.80)^{2}+(0.333-1.00)^{2}+(0.556-0.148)^{2}+(0.333-0.333)^{2}}=0.985$ \\
\hline 2 & $D 2=\sqrt{(0.20-0.80)^{2}+(0.333-1.00)^{2}+(0.532-0.148)^{2}+(0.167-0.333)^{2}}=0.989$ \\
\hline 3 & $D 3=\sqrt{(0.40-0.80)^{2}+(0.667-1.00)^{2}+(0.433-0.148)^{2}+(0.333-0.333)^{2}}=0.593$ \\
\hline 4 & $D 4=\sqrt{(0.80-0.80)^{2}+(0.333-1.00)^{2}+(0.309-0.148)^{2}+(0.333-0.333)^{2}}=0.686$ \\
\hline 5 & $D 5=\sqrt{(0.40-0.80)^{2}+(0.333-1.00)^{2}+(0.828-0.148)^{2}+(0.333-0.333)^{2}}=1.03$ \\
\hline$\ldots$ & $\ldots$ \\
\hline 77 & $D 77=\sqrt{(0.60-0.80)^{2}+(1.00-1.00)^{2}+(0.093-0.148)^{2}+(0.500-0.333)^{2}}$ \\
& $=0.266$
\end{tabular}

Sumber: Pengolahan Data (2021)

e. Pengurutan jarak terkecil

Setelah melakukan pencarian jarak Euclidean maka dilakukan pengurutan data berdasarkan jarak terkecil. pengujian terhadap dataset dapat dilihat pada tabel 6 . 
Tabel 6. Pengurutan Jarak Euclidean

\begin{tabular}{ccccccc}
\hline $\begin{array}{c}\text { No } \\
\text { Dataset }\end{array}$ & $\begin{array}{c}\text { Pekerjaan } \\
\text { Orang Tua }\end{array}$ & $\begin{array}{c}\text { Status } \\
\text { Orang } \\
\text { Tua }\end{array}$ & $\begin{array}{c}\text { Penghasilan } \\
\text { Orang Tua }\end{array}$ & $\begin{array}{c}\text { Jumlah } \\
\text { Tanggun } \\
\text { gan } \\
\text { Orang } \\
\text { Tua }\end{array}$ & Hasil & $\begin{array}{c}\text { Jarak } \\
\text { Euclidean }\end{array}$ \\
\hline 202011 & 0.8 & 1.000 & 0.148 & 0.333 & Ya & 0.000 \\
\hline 202015 & 1 & 1.000 & 0.111 & 0.333 & Ya & 0.203 \\
\hline 202077 & 0.6 & 1.000 & 0.093 & 0.500 & Ya & 0.266 \\
\hline 202066 & 0.8 & 1.000 & 0.049 & 0.667 & Ya & 0.348 \\
\hline 202020 & 0.6 & 1.000 & 0.124 & 0.667 & Ya & 0.390 \\
\hline 202027 & 1 & 0.667 & 0.124 & 0.500 & Ya & 0.424 \\
\hline 202003 & 0.4 & 0.667 & 0.433 & 0.333 & Tidak & 0.593 \\
\hline 202035 & 0.8 & 0.333 & 0.111 & 0.333 & Ya & 0.668 \\
\hline 202041 & 0.8 & 0.333 & 0.087 & 0.333 & Tidak & 0.670 \\
\hline 202061 & 0.8 & 0.333 & 0.049 & 0.333 & Tidak & 0.674 \\
\hline
\end{tabular}

Sumber: Pengolahan Data (2021)

Pada Tabel 6 dapat dilihat data dengan dengan hasil Ya muncul dengan proporsi 70\%, sedangkan kelas Tidak sebesar 30\%, dapat disimpulkan atas nama Muhammad Haikal Nafis masuk ke hasil $\mathrm{Ya} /$ Layak dengan menggunakan nilai $\mathrm{k}=10$. Syarat untuk mendapatkan hasil target $\mathrm{Ya}($ true) atau Tidak(false) tersebut yaitu hasil memiliki data target yang muncul dengan jumlah terbanyak. Pemilihan tersebut maka akan menemukan hasil prediksi pada data yang diuji tersebut.

f. Akurasi

Pada pencarian nilai akurasi menggunakan tabel confusion matrix. Pencarian dengan confusion matrix menggunakan data hasil, aktual adalah data sebelum diuji, sedangkan prediksi yaitu data yang telah diuji dengan metode K-Nearest Neighbor, seluruh data telah diuji dengan metode tersebut. Pada pengujian ini telah didapat hasil prediksi seluruh data yang telah diuji. Data dapat dilihat pada tabel confusion matrix dengan persamaan yang dapat dilihat pada tabel 7 .

Tabel 7. Tabel Confusion Matrix

\begin{tabular}{cccc}
\hline $\mathbf{N}=77$ & Kelas & Prediksi \\
Aktual & True & True & False \\
& False & 5 & 7 \\
& & 0 & 65 \\
\hline Sumber: Pengolahan Data (2021) & &
\end{tabular}

Tabel confusion matrix terdapat data True Positive (TP) sejumlah 5 data, False Positive (FP) sejumlah 7 data, True Negative (TN) sejumlah 65 data dan False Negative (FP) sejumlah 0 . Untuk dapat menjadi acuan evaluasi dan mencari akurasi dapat dilihat pada data dibawah ini.

$$
\text { Akurasi }=\frac{5+65}{77} * 100=90.90 \%
$$




\section{Tampilan Sistem Informasi Pemilihan Peserta Program Indonesia Pintar (PIP)}

Pada tahapan ini merupakan implementasi yang dilakukan dengan cara pengkodean program.

a. Tampilan Data Atribut

Gambar 4 yang terlihat merupakan tampilan dari halaman data Atribut pada sistem informasi pemilihan peserta PIP. Data itu berupa Kode, Nama Atribut, Status Atribut, Nilai, Keterangan dan Aksi (Ubah/Hapus).
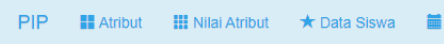

Co Logout

\section{Atribut}

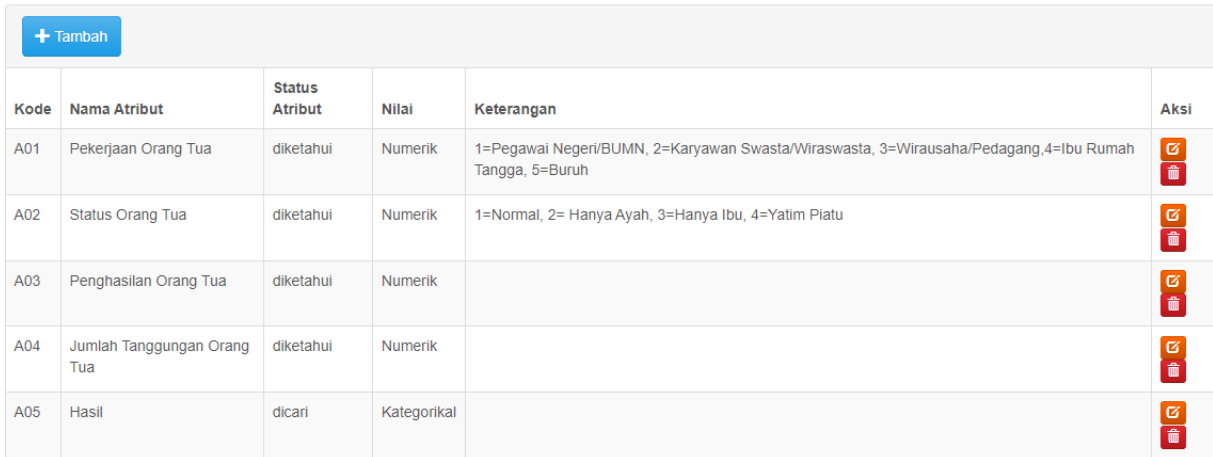

Sumber: Hasil Penelitian (2021)

Gambar 4. Menu Data Atribut

b. Tampilan Data Nilai Atribut

Gambar 5 yang terlihat merupakan tampilan dari halaman data Nilai Atribut pada sistem informasi pemilihan peserta PIP. Data ini berupa tabel dengan kolom No, Kode, Nama Atribut, Nilai Atribut dan Aksi (Ubah/Hapus).

Nilai Atribut

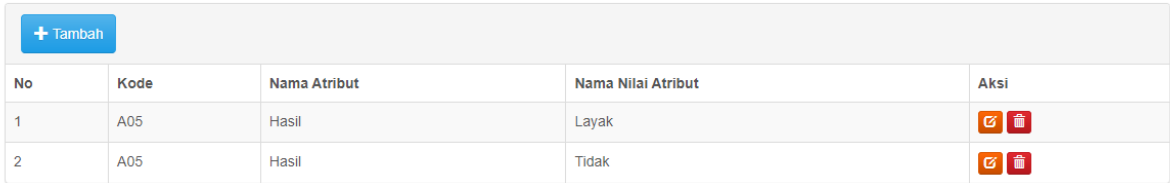

Sumber: Hasil Penelitian (2021)

Gambar 5. Menu Data Nilai Atribut

c. Tampilan Data Siswa

Gambar 6. yang terlihat merupakan tampilan dari halaman Data Siswa pada sistem informasi pemilihan peserta PIP. Data ini berupa tabel dengan kolom Nomor, Pekerjaan Orang Tua, Status Orang Tua, Penghasilan Orang Tua, Jumlah Tanggungan Orang Tua, Hasil/Target dan Aksi (Ubah/Hapus). 


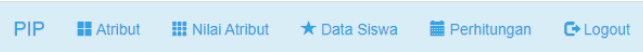

Data Siswa

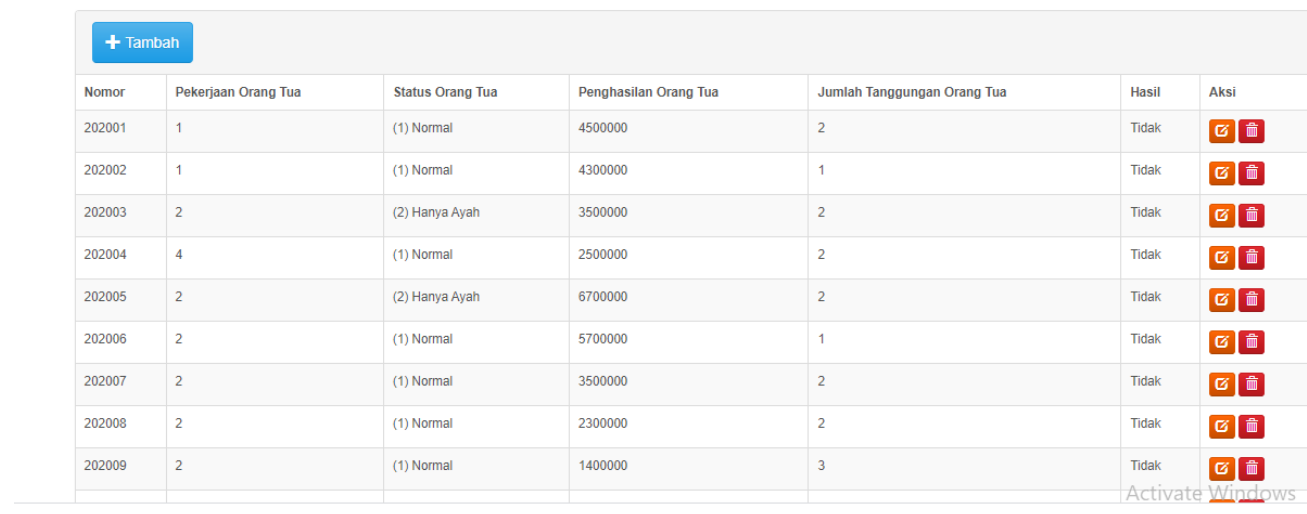

Sumber: Hasil Penelitian (2021)

\section{Gambar 6. Menu Data Siswa}

d. Tampilan perhitungan

Gambar 7 yang terlihat merupakan tampilan isian form dari halaman Perhitungan pada sistem informasi pemilihan peserta PIP. Data yang dapat diisi Pekerjaan Orang Tua, Status Orang Tua, Penghasilan Orang Tua, dan Jumlah Tanggungan Orang Tua. Terdapat tombol Hitung untuk dapat melihat hasil dari perhitungan dan mengetahui Target, target tersebut dapat berupa Layak atau Tidak Layak.

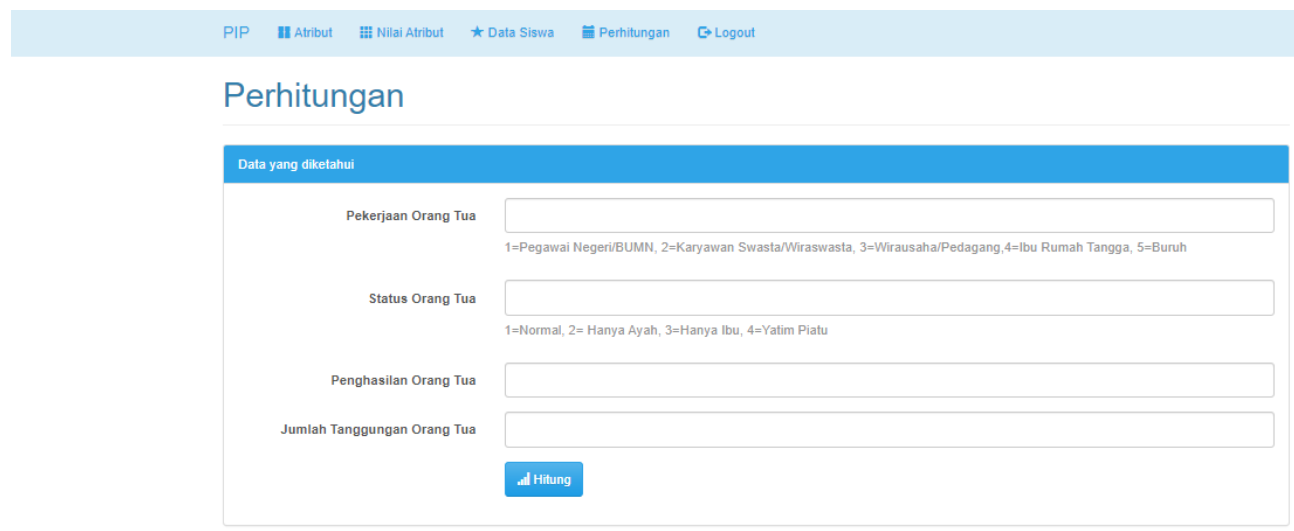

Sumber: Hasil Penelitian (2021)

Gambar 7. Menu Perhitungan

\section{Kesimpulan}

Berdasarkan dari hasil penelitian yang dilakukan, maka sistem informasi pemilihan peserta ini dapat membantu Staff Administrasi dan pihak sekolah berdasarkan kriteria pekerjaan orang tua, status orang tua, penghasilan orang tua dan jumlah tanggungan orang tua. Pemilihan peserta ini dapat terintegrasi dengan sistem menggunakan metode K-Nearest Neighbor, dalam proses perhitungan dan pengujian dari data siswa SD Negeri Pejuang V Kota Bekasi menambahkan keakuratan dalam pemilihan peserta Program Indonesia Pintar (PIP). Data siswa yang didapat sebanyak 77 siswa, terdapat data True Positive (TP) sejumlah 5 data, 
False Positive (FN) sejumlah 7 data, True Negative (TN) sejumlah 65 data dan False Negative (FP) sejumlah 0 . Hasil akurasi yang diperoleh mendapatkan nilai $90.90 \%$ dengan nilai $k=10$.

\section{Daftar Pustaka}

Argina, A. M. (2020). Penerapan Metode Klasifikasi K-Nearest Neigbor pada Dataset Penderita Penyakit Diabetes. Indonesian Journal of Data and Science, 1(2), 29-33. https://doi.org/10.33096/ijodas.v1i2.11

Harsemadi, G., Sudarma, M., \& Pramaita, N. (2017). Implementasi Algoritma K-Nearest Neighbor pada Perangkat Lunak Pengelompokan Musik untuk Menentukan Suasana Hati. Majalah Ilmiah Teknologi Elektro, 16(1), 14-20. https://doi.org/10.24843/mite.1601.03

Kemdikbud. (2021). Program Indonesia Pintar. Https://Pip.Kemdikbud.Go.Id/Home. https://pip.kemdikbud.go.id/home

Kemendikbud. (2020). Peraturan Menteri Pendidikan dan Kebudayaan Republik Indonesia Nomor 10 Tahun 2020 Tentang Program Indonesia Pintar.

Kurniawan, D., \& Saputra, A. (2019). Penerapan K-Nearest Neighbour dalam Penerimaan Peserta Didik dengan Sistem Zonasi. Jurnal Sistem Informasi Bisnis, 9(2), 212. https://doi.org/10.21456/vol9iss2pp212-219

Larose, D T. (2005). An Introduction to Data Mining. In Discovering Knowledge in Data: An Introduction to Data Mining. 4(3).

Larose, Daniel T, \& Larose, C. D. (2014). Discovering Knowledge in Data An Introduction to Data Mining Second Edition Wiley Series on Methods and Applications in Data Mining.

Latifah, R., Susilowati, E., \& Febriyanti, W. (2017). Sistem Pendukung Keputusan Penetuan Calon Penerima Kartu Jakarta Pintar ( KJP ) Menggunakan K-Nearest Neighbor. Jurnal Sistem Informasi, Teknologi Informatika Dan Komputer, 8(2), 97-104.

Negara, E. S., Romindo, R., Tanjung, R., Heriyani, R., Simarmata, N., Jamaludin, J., Putra, J., Sudarmanto, T. A. E., Sudarsono, E., \& Purba, B. (2021). Sistem Informasi Manajemen Bisnis. Yayasan Kita Menulis.

Ropianto, M., Permatasari, R. D., Hayadi, B. H., \& Rukun, K. (n.d.). Algoritma \& Pemrograman. Deepublish.

Tan, P. N., Steinbach, M., Karpatne, A., \& Kumar, V. (2006). Introduction to Data Mining. Addison-Wesley.

Yulianti, E., \& Nurdin, Y. A. (2018). Sistem Pendukung Keputusan Penerimaan Bantuan Siswa Miskin (BSM) Berbasis Online dengan Metode Knn (K-Nearest Neighbor) (Studi kasus: SMPN 1 Koto XI Tarusan). Jurnal Teknoif, 6(1), 12-17. 